\title{
Urinary Kallikrein Excretion in Essential and Mineralocorticoid Hypertension
}

\author{
O. Bryan Holland, James M. Chud, and Helen Braunstein, Department of \\ Internal Medicine, University of Texas Health Science Center, Dallas, Texas 75235
}

A B S T R A C T Urinary kallikrein excretion has been
reported to be decreased in patients with essential
hypertension and elevated in patients with primary
aldosteronism as a reflection of mineralocorticoid
activity. Low renin essential hypertension (LREH) has
been postulated to result from excess production of
an unknown mineralocorticoid(s). Urinary kallikrein
excretion was compared in outpatients with essential
hypertension, mineralocorticoid hypertension (primary
aldosteronism and $17 \alpha$-hydroxylase deficiency), and
in normal subjects of the same race. No significant
difference in urinary kallikrein excretion of patients
with LREH vs. normal renin essential hypertension
(NREH) was found for either black ( $4.1 \pm 0.4$ vs. 4.8
\pm 0.5 esterase units $(\mathrm{EU}) / 24 \mathrm{~h}$, mean $\pm \mathrm{SE}$, for $27 \mathrm{LREH}$ and $38 \mathrm{NREH}$, respectively) or white patients (12.2 \pm 2.3 vs. $11.7 \pm 1.4 \mathrm{EU} / 24 \mathrm{~h}$ for $13 \mathrm{LREH}$ and $25 \mathrm{NREH}$, respectively). Urinary kallikrein was decreased in black vs. white hypertensive patients and normal subjects. However, in patients with normal renal function (creatinine clearance $\geq 80 \mathrm{ml} / \mathrm{min}$ ) urinary kallikrein was not significantly decreased in either black hypertensive vs. black normal subjects $(4.3 \pm 0.3$ vs. $5.4 \pm 0.6$ $\mathrm{EU} / 24 \mathrm{~h}$ ) or in white hypertensive vs. white normal subjects $(11.9 \pm 1.2$ vs. $8.4 \pm 0.9 \mathrm{EU} / 24 \mathrm{~h})$. In contrast, hypertensive patients with mild renal insufficiency (creatinine clearance of $41.8 \pm 78.5 \mathrm{ml} / \mathrm{min}$ ) had reduced $(P<0.05)$ urinary kallikrein $(3.3 \mathrm{EU} / 24 \mathrm{~h}$ with creatinine clearance of $63.6 \pm 2.0$ for 24 black patients and $4.2 \pm 0.7$ $\mathrm{EU} / 24 \mathrm{~h}$ with creatinine clearance of $67.0 \pm 3.5$ for 6 white patients). These results suggest that a reduction in urinary kallikrein excretion rate is an early accompaniment of hypertensive renal injury. Urinary kallikrein excretion in response to a 6-d 10-meq sodium diet and a 3-d Florinef ( $0.5 \mathrm{mg}$ b.i.d.) administration was compared in hypertensive patients with normal renal func-

A preliminary report of the data was presented at the Southern Section Meeting of The American Federation for Clinical Research in New Orleans, La. in January 1976.

Received for publication 1 May 1978 and in revised form 5 October 1979. tion vs. race and age-matched normal subjects. Stimulation of urinary kallikrein excretion by Florinef was equal in black and white normal subjects vs. hypertensive patients (black normals $=12.3 \pm 2.7[n=9]$, $\mathrm{NREH}=11.7 \pm 1.8[n=10], \mathrm{LREH}=10.9 \pm 1.5[n=12]$; white normals $=21.2 \pm 2.9[n=11]$, essential hypertension $=20.9 \pm 3.2[10 \mathrm{NREH}, 5 \mathrm{LREH}])$. Stimulation of urinary kallikrein excretion with low sodium diet was decreased $(P<0.05)$ only in black LREH (black normals $=11.2 \pm 2.4 \quad[n=10], \quad \mathrm{NREH}=10.1 \pm 2.7 \quad[n$ $=10]$, LREH $=7.4 \pm 1.1[n=13]$; white normals $=19.1$ $\pm 2.7[n=13$ ], essential hypertension $=17.5 \pm 2.3$ [nine NREH, four LREH]). However, during low sodium diet, black patients with LREH had evidence for less sodium depletion as manifested by a decreased rise in urinary aldosterone excretion ( $16.3 \pm 2.7$ vs. $33.3 \pm 6.4$ $\mu \mathrm{g} / 24 \mathrm{~h}$ for black normals) and a failure to achieve metabolic balance in 11/13 patients. Thus, the lesser kallikrein stimulation appeared to result from these two factors. Black and white hypertensives with creatinine clearance $<80 \mathrm{ml} / \mathrm{min}$ had little increase in urinary kallikrein excretion with Florinef or low sodium diet.

5 of 12 patients with primary aldosteronism or $17 \alpha$ hydroxylase deficiency did not have an elevated urinary kallikrein excretion rate. Mild renal insufficiency may have contributed to this finding in two of these five patients. Nevertheless, this finding illustrates a limitation to the use of urinary kallikrein excretion rate as an index of mineralocorticoid activity. However, it appears that the majority of patients with LREH have no evidence for excess production of an unknown mineralocorticoid. The failure to find a decrease in urinary kallikrein excretion in racially matched patients with essential hypertension and normal renal function questions the postulate of a role of the kallikrein-kinin system in the initiation of essential hypertension.

\section{INTRODUCTION}

In 1934 Elliot and Nuzum noted that hypertensive patients had a decrease in urinary kallikrein excretion 
(1). Subsequent investigators (2-6) confirmed this observation but noted an increase in urinary kallikrein in patients with primary aldosteronism, in patients and experimental animals administered mineralocorticoids, and in normal subjects during low sodium diet. These increases could be blocked by the administration of spironolactone, a mineralocorticoid antagonist. Margolius et al. $(3,4)$, thus, proposed that urinary kallikrein excretion rate reflects the activity of circulating mineralocorticoids upon the kidney. Excess production of an unknown mineralocorticoid(s) has been proposed (7) to be the cause of low renin essential hypertension (LREH). ${ }^{1}$ Thus, urinary kallikrein excretion might be expected to be elevated in that subgroup of patients with LREH secondary to mineralocorticoid overproduction. The following studies were performed to compare urinary kallikrein excretion rate in normal subjects and patients with essential and mineralocorticoid hypertension while they consumed their usual diet and during stimulation of kallikrein excretion with low sodium diet and the administration of exogenous mineralocorticoid.

\section{METHODS}

Patient population. The diagnosis of essential hypertension was established after history, physical examination, blood

\footnotetext{
${ }^{1}$ Abbreviations used in this paper: $\mathrm{C}_{\mathrm{cr}}$, creatinine clearance; EU, esterase units; LREH, low renin essential hypertension; PRA, plasma renin activity.
}

chemistry studies using an automated multiple analysis system (SMA-12), urinalysis, urinary metanephrine, and rapidsequence intravenous pyelogram revealed no evidence of secondary forms of hypertension. Patients were then classified into low, normal, and high renin subgroups on the basis of the plasma renin activity (PRA) response to $40 \mathrm{mg}$ of intravenous furosemide (8). While consuming their usual diet, hypertensive patients collected $24-\mathrm{h}$ urine samples and refrigerated these throughout the time of collection. Most patients had received previous instructions and encouragement to consume a no-added-salt diet, though they were not encouraged again to adhere to this diet during the study period. Adequacy of the collection was assessed by determining 24 -h creatinine excretion, and determination of simultaneous plasma creatinine enabled calculation of creatinine clearance $\left(\mathrm{C}_{\mathrm{cr}}\right)$ as an index of glomerular filtration rate and renal function. Hypertensive patients were subdivided into those with $\mathrm{C}_{\mathrm{cr}}$ above and below $80 \mathrm{ml} / \mathrm{min}$. All patients had been off antihypertensive medications for at least 3 wk before any study.

In addition to these outpatient studies, normal subjects and hypertensive patients entered the General Clinical Research Center at Parkland Memorial Hospital for metabolic diet. During the first protocol, the patients received a 200-meq $\mathrm{Na}^{+}, 70$-meq $\mathrm{K}^{+}$diet for 5 or $6 \mathrm{~d}$. During the last $3 \mathrm{~d}$ Florinef (fludrocortisone acetate, $0.5 \mathrm{mg}$ b.i.d.) was administered. During the other protocol, a $120-$ meq $\mathrm{Na}^{+}$, 70 -meq $\mathrm{K}^{+}$diet for $3 \mathrm{~d}$ and a 10 -meq $\mathrm{Na}^{+}, 70$-meq $\mathrm{K}^{+}$diet for $6 \mathrm{~d}$ was consumed. Daily refrigerated 24 -h urine samples were collected for aldosterone, kallikrein, sodium, potassium, and creatinine determination. Each night the patient retired to bed at 22302300 and remained at absolute bed rest from at least 0200 until 0600 when blood was drawn. The fasting patient then ambulated 0600-0800 and blood was again taken for determination of PRA. After a 6-d 10-meq $\mathrm{Na}^{+}$diet, the fasting patient ambulated 0600-1000 before blood was taken for determina-

TABLE I

Urinary Kallikrein Excretion in Patients with Mineralocorticoid Hypertension

\begin{tabular}{|c|c|c|c|c|c|c|c|c|c|c|c|}
\hline \multirow[b]{2}{*}{ No. } & \multirow[b]{2}{*}{ Race } & \multirow[b]{2}{*}{ Age } & \multirow[b]{2}{*}{ Kallikrein } & \multirow[b]{2}{*}{$\mathrm{C}_{\mathrm{cr}}$} & \multirow[b]{2}{*}{$\begin{array}{c}\text { Urinary } \\
\text { aldosterone }\end{array}$} & \multirow[b]{2}{*}{ PRA } & \multirow[b]{2}{*}{$\begin{array}{l}\text { Plasma } \\
\mathrm{K}^{+}\end{array}$} & \multicolumn{2}{|c|}{ Saline infusion } & \multicolumn{2}{|c|}{ Florinef suppression } \\
\hline & & & & & & & & $\mathrm{PA}^{*} / 2 \mathrm{~h} \uparrow$ & $\mathrm{PA} / \mathbf{4} \mathrm{h} \rightarrow$ & PA/0600 $\rightarrow$ & $\begin{array}{c}\text { Urinary } \\
\text { aldosterone }\end{array}$ \\
\hline & & & $E U / 24 h$ & $\mathrm{ml} / \mathrm{min}$ & $\mu g / 24 h$ & $n g / m l / h$ & meq/liter & $n g / d l$ & $n g / d l$ & $n g / d l$ & $\mu g / 24 h$ \\
\hline \multicolumn{12}{|c|}{ Primary aldosteronism } \\
\hline 1 & W & 54 & 12.3 & 96.3 & 20.0 & 0.1 & 2.5 & 68.4 & $\mathbf{5 7 . 0}$ & & \\
\hline 2 & W & 66 & 5.7 & 92.6 & 11.4 & 0.1 & 2.4 & 17.7 & 3.2 & 14.1 & 10.3 \\
\hline 3 & W & 71 & 16.7 & 56.4 & 19.8 & 0.1 & 2.3 & & & & \\
\hline 4 & W & 57 & 24.3 & 95.0 & 20.3 & 0.3 & 3.2 & 27.5 & 4.2 & & \\
\hline 5 & W & 43 & 10.0 & 76.2 & 22.6 & 1.4 & 2.8 & 36.4 & 15.0 & 32.2 & 28.8 \\
\hline 6 & W & 23 & 29.3 & 142.3 & 59.0 & 0.4 & 2.5 & 78.1 & 45.5 & 38.6 & 17.6 \\
\hline 7 & B & 69 & 3.1 & 125.1 & 32.6 & 0.1 & 2.8 & 69.8 & 22.2 & 33.7 & 10.2 \\
\hline 8 & B & 45 & 24.7 & 109.6 & 20.0 & 0.3 & 3.5 & 25.7 & 8.0 & 11.7 & 9.2 \\
\hline 9 & B & 31 & 14.1 & 129.2 & 48.9 & 0.1 & 2.8 & 45.3 & 19.0 & 33.2 & 26.9 \\
\hline 10 & B & 58 & 18.0 & 88.8 & 29.2 & 0.5 & 2.5 & 34.7 & 27.9 & & \\
\hline 11 & B & 42 & 15.5 & 111.4 & 18.0 & 0.5 & 3.5 & 17.1 & 5.4 & 5.5 & 13.4 \\
\hline
\end{tabular}

$17 \alpha$-Hydroxylase deficiency
12
B 24
17.6
100.8
2.0
0.1
2.8

* B, black; W, white; PA, plasma aldosterone; $2 \mathrm{~h} \uparrow=$ after a 2 -h ambulation; $4 \mathrm{~h} \rightarrow=$ after $4 \mathrm{~h}$ supine with a 2 -liter saline infusion; PA/0600 $\rightarrow=$ supine 0600 PA after a 3-d Florinef administration (0.5 mg b.i.d.).

Florinef urinary aldosterone was determined on the 3rd $\mathrm{d}$ of Florinef administration. 
tion of PRA. At least 2 wk elapsed between each admission for these protocols.

Patients with primary aldosteronism were identified with criteria noted in Table I. Normal 24-h urinary aldosterone excretion (mean $\pm 2 \mathrm{SD}$ ) determined in normal subjects (Table II) on their usual diet was 0-15.7 $\mu \mathrm{g}$ for black subjects and 1.2-13.4 $\mu \mathrm{g}$ for white subjects with a range up to 18.8 and $16.1 \mu \mathrm{g}$ for black and white normal subjects, respectively. Low PRA after $2 \mathrm{~h}$ of ambulation or with the intravenous furosemide test $(8)$ is $<0.6$ and $<1.0 \mathrm{ng} / \mathrm{ml}$ per $\mathrm{h}$ for black and white subjects, respectively. Plasma aldosterone after saline infusion into normal subjects has been reported to fall to $<5(9)$ or $9 \mathrm{ng} / \mathrm{dl}(10)$ or to $<25 \%$ of the base line. The protocol with Florinef administration in conjunction with a 200-meq $\mathrm{Na}^{+}$diet has also been used as an additional suppressive maneuver to identify patients with primary aldosteronism (Table I). A 3-d Florinef administration to 17 normal subjects suppressed supine plasma aldosterone concentration $(0600)$ to $<5.0 \mathrm{ng} / \mathrm{dl}$, urinary aldosterone excretion to $<6.0 \mu \mathrm{g} / 24 \mathrm{~h}$, and urinary tetrahydroaldosterone to $<34 \mu \mathrm{g} / 24 \mathrm{~h}$. Though some of the usual criteria for primary aldosteronism were normal in patient 2 , this patient had consistent severe hypokalemia, metabolic alkalosis, suppressed PRA, and failure to suppress plasma and urinary aldosterone normally with Florinef. In addition, urinary tetrahydroaldosterone, a more satisfactory index of aldosterone production, has been elevated during regular sodium diet, a $200-$ meq $\mathrm{Na}^{+}$diet, and a $200-\mathrm{meq}$ $\mathrm{Na}^{+}$diet plus Florinef (range of 72-135 $\mu \mathrm{g} / 24 \mathrm{~h}$; normal up to $60 \mu \mathrm{g} / 24 \mathrm{~h}$ on regular sodium outpatient diet for normal subjects. ${ }^{2}$ The diagnosis of primary aldosteronism was based on elevated 24-h urinary aldosterone excretion in conjunction with hypokalemia and low PRA in patients 3 and 4 . Histological confirmation of bilateral hyperplasia in patients 1 and 5 and a unilateral adenoma in patient 6 was obtained. All patients with primary aldosteronism have responded to spironolactone therapy with correction of their hypokalemic alkalosis and resolution or improvement in their hypertension.

Urinary kallikrein excretion rate was also determined in one black male pseudohermaphrodite with complete deficiency of $17 \alpha$-hydroxylase (11) who has been followed at Parkland Memorial Hospital since the time of birth in 1954. The patient has hypertension; hypokalemia; secretion rates of deoxycorticosterone, corticosterone, aldosterone, and cortisol of

${ }^{2}$ Unpublished radioimmunoassay method.

TABLE II

Urinary Kallikrein, Aldosterone, Sodium, and Potassium Excretion and $C_{C r}$ in Normal Subjects and Hypertensive Patients*

\begin{tabular}{|c|c|c|c|c|c|c|c|c|c|}
\hline & No. & Age & Kallikrein & Aldosterone & Sodium & Potassium & Creatinine & $\mathrm{C}_{\mathrm{cr}}$ & PRA \\
\hline & & $y r$ & $E U / 24 h$ & $\mu g / 24 h$ & $m e q / 24 h$ & $m e q / 24 h$ & $m g / 24 h$ & $\mathrm{ml} / \mathrm{min}$ & $n g / m l / h$ \\
\hline Normal black & 34 & $41 \pm 2$ & $5.4 \pm 0.6$ & $7.1 \pm 0.7$ & $155 \pm 11$ & $45 \pm 4$ & $1,429 \pm 81$ & & \\
\hline Women & 22 & $41 \pm 2$ & $5.2 \pm 0.8$ & $7.2 \pm 1.0$ & $151 \pm 12$ & $44 \pm 5$ & $1,186 \pm 76$ & & \\
\hline Men & 12 & $41 \pm 2$ & $5.8 \pm 0.9$ & $7.0 \pm 1.1$ & $168 \pm 1$ & $48 \pm 7$ & $1,813 \pm 110$ & & \\
\hline Normal white & 37 & $43 \pm 2$ & $8.4 \pm 0.9 \ddagger$ & $7.3 \pm 0.5$ & $162 \pm 10$ & $56 \pm 3 \S$ & $1,295 \pm 66$ & & \\
\hline Women & 22 & $45 \pm 2$ & $8.8 \pm 1.2$ & $7.7 \pm 0.7$ & $160 \pm 14$ & $55 \pm 4$ & $1,083 \pm 47$ & & \\
\hline Men & 15 & $41 \pm 3$ & $7.7 \pm 1.0$ & $6.7 \pm 0.7$ & $166 \pm 13$ & $58 \pm 4$ & $1,632 \pm 83$ & & \\
\hline Hypertensive black & 65 & $49 \pm 1$ & $4.3 \pm 0.3$ & $5.3 \pm 0.4$ & $157 \pm 8$ & $36 \pm 2$ & $1,452 \pm 45$ & $102.6 \pm 2.3$ & $1.5 \pm 0.4$ \\
\hline Women & 46 & $48 \pm 2$ & $4.6 \pm 0.4$ & $5.6 \pm 0.4$ & $160 \pm 9$ & $37 \pm 2$ & $1,315 \pm 34$ & $101.3 \pm 2.6$ & $1.4 \pm 0.5$ \\
\hline Men & 19 & $53 \pm 3$ & $3.7 \pm 0.5$ & $4.6 \pm 0.6$ & $155 \pm 16$ & $40 \pm 4$ & $1,891 \pm 99$ & $109.4 \pm 6.0$ & $1.9 \pm 0.5$ \\
\hline Normal renin & 38 & $46 \pm 2$ & $4.8 \pm 0.5$ & $5.0 \pm 0.5$ & $155 \pm 9$ & $39 \pm 2$ & $1,453 \pm 57$ & $105.0 \pm 3.2$ & $1.9 \pm 0.3$ \\
\hline Low renin & 27 & $53 \pm 2$ & $4.1 \pm 0.4$ & $5.7 \pm 0.5$ & $185 \pm 11 \S \S$ & $39 \pm 3$ & $1,452 \pm 73$ & $99.3 \pm 3.4$ & $0.3 \pm 0.1$ \\
\hline Hypertensive white & 38 & $43 \pm 2$ & $11.9 \pm 1.2 \pi$ & $9.5 \pm 0.8$ & $171 \pm 10$ & $56 \pm 39$ & $1,464 \pm 70$ & $105.0 \pm 4.0$ & $2.6 \pm 0.5 \ddagger$ \\
\hline Women & 17 & $43 \pm 3$ & $11.4 \pm 1.4$ & $9.8 \pm 1.1$ & $142 \pm 9$ & $52 \pm 3$ & $1,205 \pm 46$ & $106.0 \pm 5.0$ & $2.2 \pm 0.5$ \\
\hline Men & 21 & $43 \pm 3$ & $12.3 \pm 1.9$ & $9.3 \pm 1.3$ & $184 \pm 15$ & $59 \pm 6$ & $1,665 \pm 98$ & $109.0 \pm 5.0$ & $3.0 \pm 0.6$ \\
\hline Normal renin & 25 & $38 \pm 2$ & $11.7 \pm 1.4$ & $9.6 \pm 1.0$ & $159 \pm 13$ & $55 \pm 4$ & $1,459 \pm 96$ & $108.0 \pm 4.0$ & $3.8 \pm 0.4$ \\
\hline Low renin & 13 & $53 \pm 3$ & $12.2 \pm 2.3$ & $9.4 \pm 1.4$ & $171 \pm 14$ & $60 \pm 6$ & $1,463 \pm 66$ & $107.0 \pm 6.0$ & $0.4 \pm 0.1$ \\
\hline \multicolumn{10}{|l|}{$\begin{array}{l}\text { Mild renal } \\
\text { insufficiency } \\
\text { Hypertensive }\end{array}$} \\
\hline black & 24 & $50 \pm 2$ & $3.3 \pm 0.4 \ddagger$ & $4.3 \pm 0.5$ & $113 \pm 8^{* *}$ & $33 \pm 2$ & $1,073 \pm 32$ & $63.6 \pm 2.0$ & $0.9 \pm 0.2$ \\
\hline \multicolumn{10}{|l|}{ Hypertensive } \\
\hline white & 6 & $57 \pm 3$ & $4.2 \pm 0.7^{\prime \prime}$ & $7.0 \pm 1.5$ & $129 \pm 28$ & $40 \pm 6$ & $1,243 \pm 105$ & $67.0 \pm 3.5$ & $1.8 \pm 0.7$ \\
\hline
\end{tabular}

* Data are expressed as mean $\pm \mathrm{SE}$.

$\$ P<0.01$ vs. normal black.

$\S P<0.05$ vs. normal black.

" $P<0.05$ vs. normal white.

I $P<0.001$ vs. hypertensive black.

** $P<0.01$ vs. hypertensive black.

\# $P<0.05$ vs. hypertensive black.

$\S \S P<0.01$ vs. normal renin black. 
$1,935 \mathrm{ng} / \mathrm{d}, 18 \mathrm{mg} / \mathrm{d}, 13.5 \mu \mathrm{g} / \mathrm{d}$, and $<1 \mathrm{mg} / \mathrm{d}$, respectively; excretion rates of estradiol and estrone of $<1 \mu \mathrm{g} / \mathrm{d}$ of each; and plasma testosterone which is undetectable. Glucocorticoid therapy reverses the hypertension and hypokalemia.

Assays. PRA was determined by radioimmunoassay of angiotensin I generated during incubation of plasma at $\mathrm{pH}$ 5.5 (12). Plasma aldosterone concentration (13) and 24-h urinary aldosterone excretion (14) were determined by radioimmunoassay. Urinary kallikrein was determined by the method of Margolius et al. (5) using human urinary kallikrein standard generously supplied by Dr. Jack Pierce of the National Institutes of Health. Urinary kallikrein determinations were not corrected for recovery because recovery of standard human urinary kallikrein added to individual desalted urine samples was found to be in excess of $90 \%$ in a large number of samples. Urine samples were refrigerated in glass vials under toluene until the time of assay. With this assay, intraassay variation is $4.0 \%$ and interassay variation of a urine pool (mean \pm 11.3 esterase units $[\mathrm{EU}] / 24 \mathrm{~h}, n=30$ ) is $10.2 \%$.

All patients gave written informed consent to participate in these studies after explanation of the study in lay language. All study protocols were approved by the Human Research Review Committee of the University of Texas Health Science Center at Dallas. Statistical evaluation of the data was performed with Student's $t$ test for unpaired observations (15).

\section{RESULTS}

The 24-h urinary kallikrein excretion rates for normal subjects and patients with normal renin essential hypertension, LREH, mineralocorticoid hypertension, and mild renal insufficiency $\left(\mathrm{C}_{\mathrm{cr}}<80 \mathrm{ml} / \mathrm{min}\right)$ are presented in Tables I and II and Figs. 1 and 2. The data of patients with essential hypertension and mild renal insufficiency have not been subdivided into low (13 black, 2 white patients) and normal renin ( 11 black, 4 white patients) categories because there were not enough patients in some subgroups to permit meaningful statistical evaluation, and no differences were found in normal vs. low renin essential hypertensives with normal renal function. The data of black and white individuals have been separated because there are known racial differences in urinary kallikrein excretion rate (16). We likewise noted decreased urinary kallikrein excretion in black vs. white normal subjects and hypertensive patients (Table II). Kallikrein excretion did not differ between women and men, between normal renin and low renin hypertensive patients, and between normal subjects and hypertensive patients of the same race. However, urinary kallikrein was significantly $(P<0.05)$ decreased in both white and black patients with essential hypertension and mild renal insufficiency (Table II). 3 of 24 black patients and 5 of 6 white patients were men with mild renal insufficiency. Urinary creatinine of sex-matched groups was similar. The range in $\mathrm{C}_{\mathrm{cr}}$ for patients with mild renal insufficiency was 41.8-77.8 $\mathrm{ml} / \mathrm{min}$ for black patients and $52.6-78.5 \mathrm{ml} / \mathrm{min}$ for white patients. There was no correlation between urinary kallikrein and $\mathrm{C}_{\mathrm{cr}}$ in white and black hypertensive patients with or without normal renal function

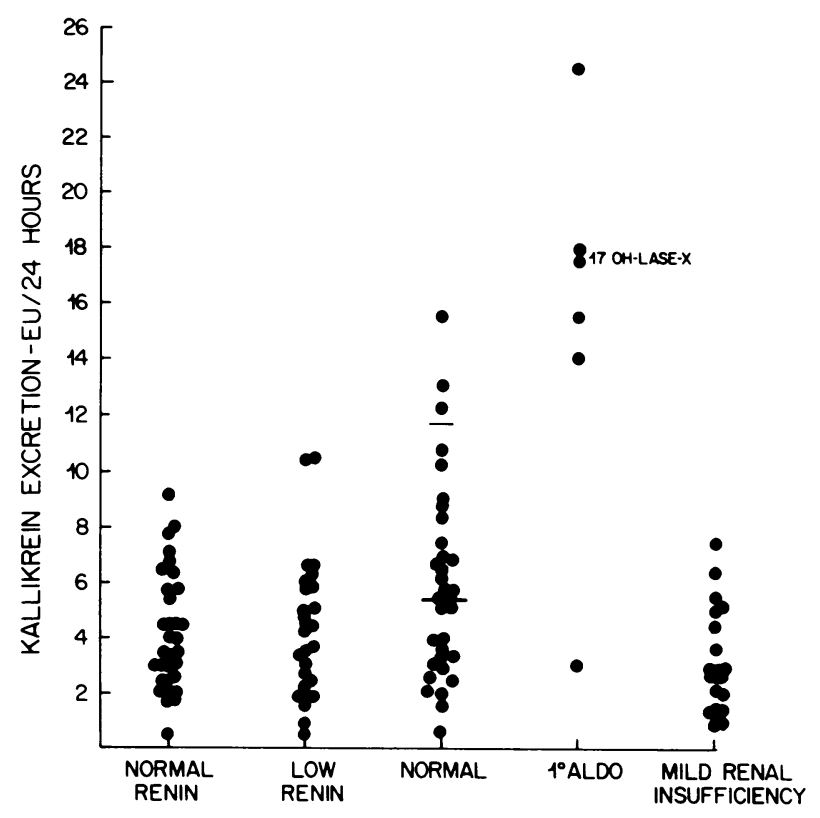

FIGURE 1 Urinary kallikrein excretion rate $(\mathrm{EU} / 24 \mathrm{~h})$ in black normal renin and low renin hypertensive patients, black normal subjects, black patients with primary aldosteronism or $17 \alpha$-hydroxylase deficiency, and black patients with essential hypertension and mild renal insufficiency (average $\mathrm{C}_{\mathrm{cr}}$ of $63.6 \mathrm{ml} / \mathrm{min}$ ). Mean $\pm 2 \mathrm{SD}$ data of the normal subjects are indicated.

or when the two subgroups were combined $(r=0.01-$ $0.08)$. The normal range for urinary kallikrein excretion $($ mean $\pm 2 \mathrm{SD}$ ) was $5.4 \pm 6.4$ and $8.4 \pm 10.2 \mathrm{EU} / 24 \mathrm{~h}$ for black and white patients, respectively. Urinary kallikrein excretion was elevated in four of five black patients with primary aldosteronism, in the one black patient with $17 \alpha$-hydroxylase deficiency, and in two of six white patients with primary aldosteronism.

Black normal subjects and hypertensive patients averaged significantly less urinary potassium excretion than white normal subjects and hypertensive patients. Kallikrein excretion did not change in white and black normal subjects and hypertensive patients of different ages (Table III), though too few subjects above age 60 were available to provide meaningful data above this age (Table III). PRA with the intravenous furosemide test $(8)$ was lower $(P<0.01)$ in black vs. white hypertensive patients, as previously reported (8). Urinary sodium excretion was significantly higher $(P<0.01)$ in black low renin vs. normal renin patients and in hypertensive black patients vs. hypertensive black patients with mild renal insufficiency. No reasons for these differences in sodium excretion are apparent. As previously reported (4), there was no correlation of urinary sodium and urinary kallikrein excretion in black $(r$ $=0.01)$ or white $(r=0.08)$ normal subjects or black $(r=0.01)$ or white $(r=0.08)$ hypertensive patients.

Urinary kallikrein excretion was also determined in 


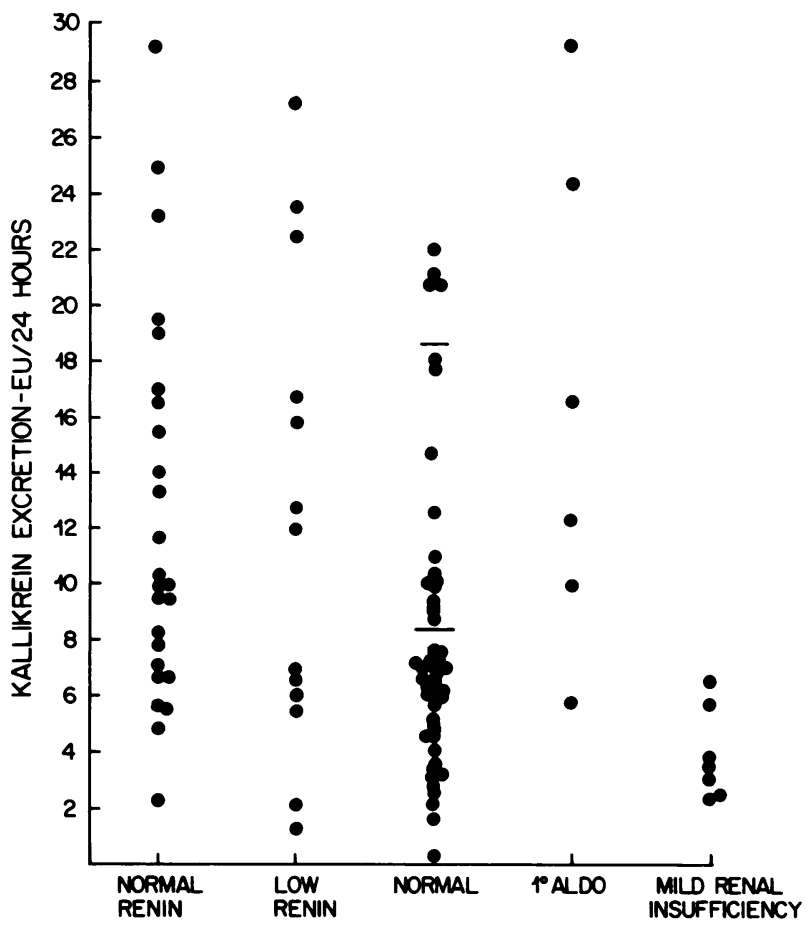

FIGURE 2 Urinary kallikrein excretion (EU/24 h) in white normal renin and low renin hypertensive patients, white normal subjects, white patients with primary aldosteronism, and white patients with essential hypertension and mild renal insufficiency (average $\mathrm{C}_{\mathrm{cr}}$ of $67.0 \mathrm{ml} / \mathrm{min}$ ). Mean $\pm 2 \mathrm{SD}$ data of the normal subjects are indicated.

black and white hypertensive patients vs. normal subjects before and during administration of Florinef (Figs. 3 and 4) and before and during low sodium diet (Figs. 5 and 6; Table IV). Hypertensive patients were divided into those with endogenous $C_{c r}$ above and below 80 $\mathrm{ml} / \mathrm{min}$. There was no significant difference in urinary kallikrein excretion after a 3-d Florinef administration

TABLE III

Urinary Kallikrein Excretion Rate at Different Ages*

\begin{tabular}{|c|c|c|c|c|}
\hline \multirow[b]{2}{*}{$\mathrm{Ag}$} & \multicolumn{2}{|r|}{ Black } & \multicolumn{2}{|c|}{ White } \\
\hline & No. & Kall ikrein & No. & Kall ikrein \\
\hline & & $E U / 24 h$ & & $E U / 24 h$ \\
\hline \multicolumn{5}{|c|}{ Normal subjects } \\
\hline $20-39$ & 13 & $4.9 \pm 0.7$ & 15 & $8.0 \pm 1.2$ \\
\hline $40-49$ & 13 & $6.6 \pm 1.1$ & 9 & $9.3 \pm 1.6$ \\
\hline $50-59$ & 4 & $4.0 \pm 1.0$ & 11 & $8.5 \pm 1.9$ \\
\hline$\geq 60$ & 2 & $3.4 \pm 0.2$ & 2 & $6.3 \pm 1.2$ \\
\hline \multicolumn{5}{|c|}{ Hypertensive patients } \\
\hline $20-39$ & 12 & $5.3 \pm 1.2$ & 9 & $14.1 \pm 2.6$ \\
\hline $40-49$ & 23 & $4.4 \pm 0.4$ & 4 & $15.2 \pm 4.1$ \\
\hline $50-59$ & 16 & $4.6 \pm 0.6$ & 6 & $5.8 \pm 1.4$ \\
\hline$\geq 60$ & 14 & $3.4 \pm 0.7$ & 3 & $11.1 \pm 5.6$ \\
\hline
\end{tabular}

* Data are expressed as mean $\pm \mathrm{SE}$.

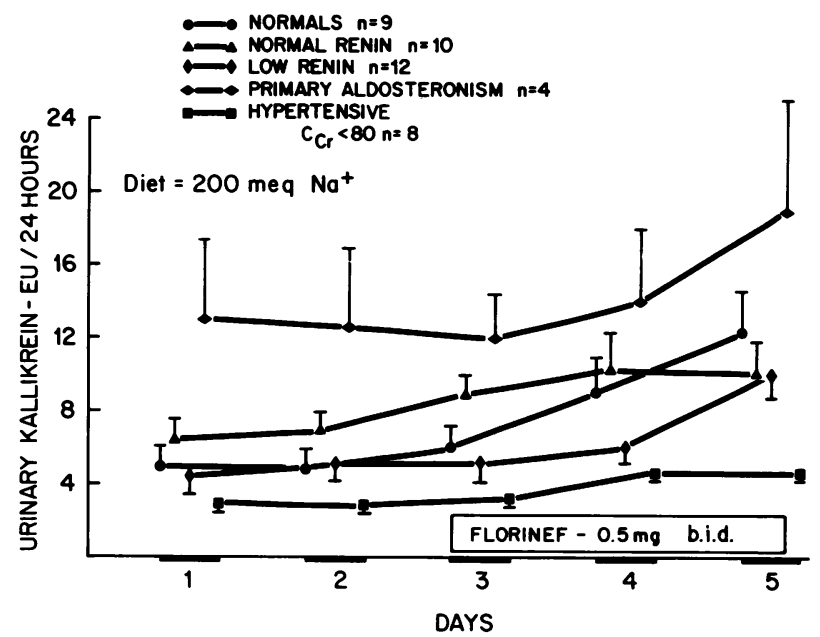

FIGURE 3 Urinary kallikrein excretion (EU/24 h; mean \pm SE) in black normal subjects and hypertensive patients before and during a 3-d administration of Florinef. Hypertensive patients have been separated into those with LREH and normal renin essential hypertension with endogenous $C_{c r}$ above $80 \mathrm{ml} / \mathrm{min}$, those with $\mathrm{C}_{\mathrm{cr}}<80 \mathrm{ml} / \mathrm{min}$, and those with primary aldosteronism.

in black hypertensive patients with $\mathrm{C}_{\mathrm{cr}}>80 \mathrm{ml} / \mathrm{min}$ vs. normal controls, though the low renin patients exhibited a slight delay in the rise in urinary kallikrein excretion (Fig. 3). Similarly, white hypertensive patients with $\mathrm{C}_{\mathrm{cr}}>80 \mathrm{ml} / \mathrm{min}$ had a normal increase in urinary kallikrein excretion in response to Florinef (Fig. 4). Black and white hypertensive patients with $\mathrm{C}_{\mathrm{cr}}<80 \mathrm{ml} / \mathrm{min}$ had little change in urinary kallikrein excretion in

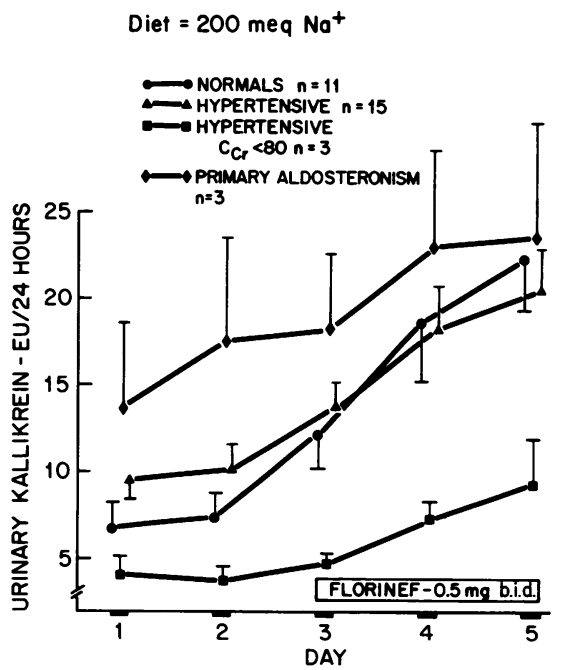

FIGURE 4 Urinary kallikrein excretion (EU/24 h; mean \pm SE) in white normal subjects and hypertensive patients before and during a 3-d administration of Florinef. Hypertensive patients ( 10 normal renin, 5 low renin) have been separated into those with endogenous $C_{c r}$ above and below $80 \mathrm{ml} / \mathrm{min}$ and those with primary aldosteronism. 
response to Florinef(Figs. 3 and 4). Patients with primary aldosteronism had a higher average base-line urinary kallikrein excretion which exhibited a further increase in Florinef.

Similarly, black normal renin and white (9/13 normal renin) hypertensive patients with $\mathrm{C}_{\mathrm{cr}}>80 \mathrm{ml} / \mathrm{min}$ exhibited about the same stimulation in urinary kallikrein excretion with a 6-d 10-meq sodium diet as did normal subjects (Figs. 5 and 6; Table IV). A lesser response was noted in low renin black hypertensives. However, these patients had evidence that less sodium depletion was produced because they exhibited a lesser rise in urinary aldosterone excretion, and only 2 or 13 patients had $<15$ meq sodium/24 h on day 6 of low sodium diet. Thus, the black low renin patients resembled the patients with primary aldosteronism in their failure to achieve sodium balance (Table IV). In contrast, all normal black subjects achieved balance after a 6-d 10-meq sodium diet. Only one of four white low renin hypertensives had $>15$ meq sodium $/ 24 \mathrm{~h}$ on day 6 of the 10-meq sodium diet.

Further evaluation of the effect of renal function on urinary kallikrein response to Florinef administration and low sodium diet was provided by dividing the black hypertensive patients into those with $\mathrm{C}_{\mathrm{cr}}<80$ $\mathrm{ml} / \mathrm{min}$, those with $\mathrm{C}_{\mathrm{cr}} 80-100 \mathrm{ml} / \mathrm{min}$, and those $\mathrm{C}_{\mathrm{cr}}$ $>100 \mathrm{ml} / \mathrm{min}$ (Fig. 7). There was a progressive increase in urinary kallikrein excretion as renal function improved. The number of white hypertensives in each of these three categories was not adequate to perform a similar detailed analysis.

\section{DISCUSSION}

Mechanisms regulating kallikrein excretion remain poorly defined at the present time. Urinary kallikrein excretion increases in normal subjects during low sodium diet (4) and in response to mineralocorticoid (4) or

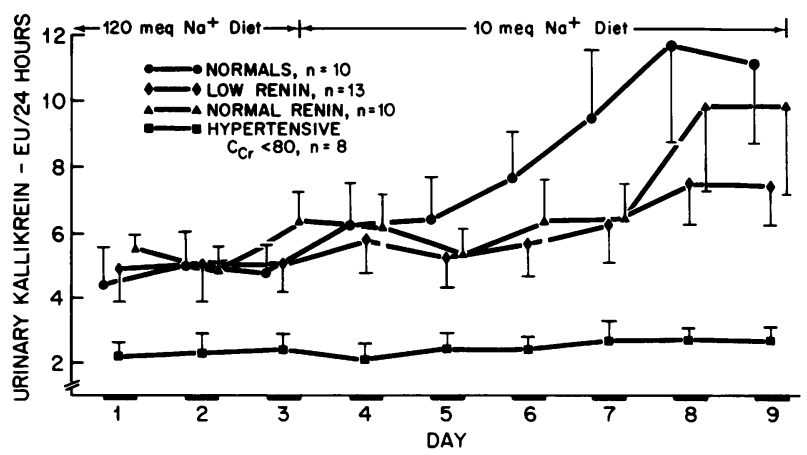

FIGURE 5 Urinary kallikrein excretion (EU/24 h; mean $\pm \mathrm{SE}$ ) in black normal subjects and hypertensive patients during a 3-d 120-meq $\mathrm{Na}^{+} / \mathrm{d}$ diet and a 6-d 10-meq $\mathrm{Na}^{+} / \mathrm{d}$ diet. Hypertensive patients have been separated into those with normal renin and low renin hypertension and endogenous $C_{c r}$ above $80 \mathrm{ml} / \mathrm{min}$, and those with $\mathrm{C}_{\mathrm{cr}}<80 \mathrm{ml} / \mathrm{min}$.

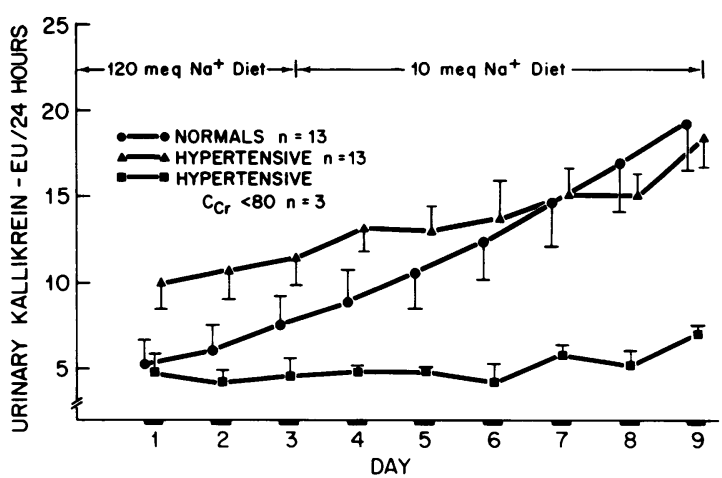

FIGURE 6 Urinary kallikrein excretion $(\mathrm{EU} / 24 \mathrm{~h}$; mean $\pm \mathrm{SE})$ in white normal subjects and hypertensive patients during a 3-d 120-meq $\mathrm{Na}^{+} / \mathrm{d}$ diet and a 6-d 10-meq $\mathrm{Na}^{+} / \mathrm{d}$ diet. Hypertensive patients (nine normal renin, four low renin) have been separated into those with endogenous $\mathrm{C}_{\mathrm{cr}}$ above and below $80 \mathrm{ml} / \mathrm{min}$.

potassium (17) administration. Increased kallikrein excretion in primary aldosteronism was noted in 9 or 10 patients by Margolius et al. (3), 3 of 9 patients by Seino et al. (18), and 4 of 6 patients by Lechi et al. (19). This gives a combined incidence of elevated urinary kallikrein excretion in $64 \%$ of patients with primary aldosteronism. Increased urinary kallikrein excretion in the one patient with $17 \alpha$-hydroxylase deficiency is compatible with other observed features of mineralocorticoid excess. We noted a slightly lower incidence (58\%) of elevated urinary kallikrein excretion in patients with mineralocorticoid hypertension. The reasons why some patients with primary aldosteronism do not have elevated urinary kallikrein excretion are not apparent. Acquired renal damage in some patients may decrease kallikrein excretion (20). This factor may have been of special importance in two (Nos. 3 and 5) of our patients and may have contributed to several others (Table I). The absolute levels of aldosterone should theoretically be of importance. All of our white patients except one (No. 6) had relatively modest elevations in urinary aldosterone; thus, the lower incidence of elevated urinary kallikrein may be related to this. However, one black patient (No. 7) had marked elevations in urinary and plasma aldosterone, normal creatinine clearance, and low urinary kallikrein. This patient is quite elderly (age 69) and, though no effect of age on urinary kallikrein excretion was apparent in Table III, only one patient was past age 65. Deterioration of glomerular, proximal tubular, and distal tubular function has been noted with aging $(21,22)$. Because normal urinary kallikrein excretion has not been satisfactorily established for this age group, it is possible that the age factor may have contributed. In addition, the histological type of primary aldosteronism may be of importance in influencing urinary kallikrein excretion. We have only one patient with an adrenal adenoma. Patients 
TABLE IV

Changes in Urinary Kallikrein, Sodium, Potassium, and Aldosterone after a 6-d Low Sodium Diet*

\begin{tabular}{|c|c|c|c|c|c|c|c|c|c|}
\hline & \multirow{2}{*}{$\begin{array}{c}\text { No. of } \\
\text { patients }\end{array}$} & \multicolumn{4}{|c|}{ 120-meq sodium diet } & \multicolumn{4}{|c|}{ 10-meq sodium diet } \\
\hline & & Kallikrein & Sodium & Potassium & Aldosterone & Kallikrein & Sodium & Potassium & Aldosterone \\
\hline & & $E U / 24 h$ & $m e q / 24 \mathrm{~h}$ & $m e q / 24 \mathrm{~h}$ & $\mu g / 24 h$ & $E U / 24 h$ & $m e q / 24 \mathrm{~h}$ & $m e q / 24 \mathrm{~h}$ & $\mu g / 24 h$ \\
\hline \multicolumn{10}{|l|}{ Normal subjects } \\
\hline Black & 10 & $5.0 \pm 1.1$ & $132 \pm 10$ & $47 \pm 4$ & $6.9 \pm 1.4$ & $11.2 \pm 2.4$ & $9 \pm 1$ & $57 \pm 4$ & $33.3 \pm 6.4$ \\
\hline White & 13 & $6.0 \pm 1.5$ & $125 \pm 10$ & $53 \pm 3$ & $6.4 \pm 0.8$ & $19.1 \pm 2.7$ & $7 \pm 1$ & $52 \pm 2$ & $32.5 \pm 3.2$ \\
\hline \multicolumn{10}{|c|}{$\begin{array}{l}\text { Essential hypertension } \\
\mathrm{C}_{c \mathrm{c}}>80 \mathrm{ml} / \mathrm{min}\end{array}$} \\
\hline \multicolumn{10}{|c|}{ Black } \\
\hline Low renin & 13 & $5.1 \pm 1.2$ & $117 \pm 16$ & $40 \pm 4$ & $8.2 \pm 1.1$ & $7.4 \pm 1.1$ & $25 \pm 4$ & $51 \pm 4$ & $16.3 \pm 2.7$ \\
\hline Normal renin & 10 & $5.1 \pm 0.7$ & $132 \pm 18$ & $42 \pm 4$ & $8.0 \pm 1.5$ & $10.1 \pm 2.7$ & $17 \pm 3$ & $52 \pm 3$ & $19.1 \pm 3.6$ \\
\hline White $\$$ & 13 & $10.8 \pm 2.3$ & $122 \pm 8$ & $54 \pm 2$ & $9.9 \pm 1.2$ & $17.5 \pm 2.3$ & $8 \pm 1$ & $56 \pm 2$ & $27.5 \pm 4.4$ \\
\hline \multicolumn{10}{|l|}{$\mathrm{C}_{\mathrm{cr}}<80 \mathrm{ml} / \mathrm{min}$} \\
\hline Black & 8 & $2.3 \pm 0.6$ & $123 \pm 23$ & $35 \pm 4$ & $5.2 \pm 1.4$ & $2.7 \pm 0.4$ & $24 \pm 5$ & $54 \pm 5$ & $11.5 \pm 1.8$ \\
\hline White & 3 & $4.2 \pm 0.7$ & $122 \pm 8$ & $54 \pm 2$ & $6.5 \pm 1.0$ & $7.0 \pm 0.5$ & $8 \pm 1$ & $56 \pm 2$ & $14.1 \pm 4.9$ \\
\hline \multicolumn{10}{|l|}{ Primary aldosteronism } \\
\hline $\mathrm{C}_{\mathrm{cr}}>80 \mathrm{ml} / \mathrm{min}$ & & & & & & & & & \\
\hline Black & 4 & $16.2 \pm 4.5$ & $128 \pm 40$ & $63 \pm 12$ & $29.4 \pm 4.9$ & $21.8 \pm 7.5$ & $29 \pm 6$ & $53 \pm 9$ & $37.2 \pm 5.3$ \\
\hline
\end{tabular}

* Data are expressed as mean $\pm \mathrm{SE}$.

$\ddagger$ Nine normal renin, four low renin patients.

with bilateral hyperplasia have normalization of their blood pressure in only $\sim 10 \%$ of cases after surgical removal of both adrenals (23). Clearly, therefore, mechanisms other than aldosterone excess cause hypertension in these patients. These other mechanisms may decrease urinary kallikrein excretion in some patients with bilateral hyperplasia. Individual patient data specifying the $C_{c r}$, levels of plasma and urinary aldosterone, and the histological type of primary aldosteronism in relationship to urinary kallikrein excretion were not provided by other investigators $(3,18,19)$. Thus, the reasons why urinary kallikrein is not increased in

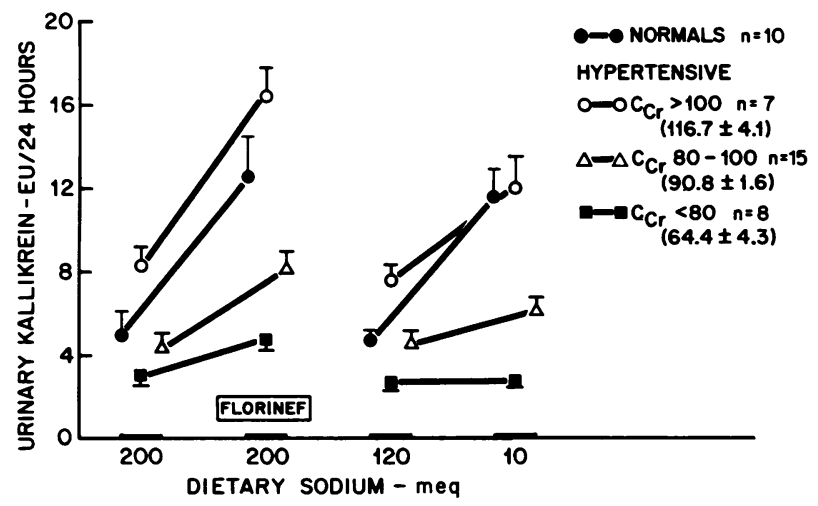

FIGURE 7 Urinary kallikrein excretion (EU/24 h; mean $\pm S E$ ) in black normal subjects and hypertensive patients before and after Florinef administration $(0.5 \mathrm{mg}$ b.i.d. for $3 \mathrm{~d}$ ) and before and after a 6-d 10-meq $\mathrm{Na}^{+}$diet. Hypertensive patients have been divided into subgroups with endogenous $\mathrm{C}_{\mathrm{cr}}$ of: $(\mathrm{l})<80$ $\mathrm{ml} / \mathrm{min}$, (2) $80-100 \mathrm{ml} / \mathrm{min}$, and (3) $>100 \mathrm{ml} / \mathrm{min}$. some patients with primary aldosteronism remain to be clarified.

Patients with LREH did not have an increase in urinary kallikrein excretion in comparison to normal renin essential hypertension or normal subjects. This finding is evidence against a mineralocorticoid etiology for LREH in the majority of patients. However, because urinary kallikrein excretion was found to be normal in a minority of patients with primary aldosteronism, the limitation of this technique for the identification of mineralocorticoid hypertension must be recognized. Nevertheless, if low renin hypertension was commonly caused by mineralocorticoid overproduction, a subgroup of patients with high normal or elevated urinary kallikrein should be seen in Figs. 1 and 2, and this is not noted. These data are difficult to reconcile with the previously reported increase in unexplained bioassayable mineralocorticoid activity in the urine of most patients with LREH (7).

The factors which cause urinary kallikrein to increase after mineralocorticoid administration remain unknown. Increased urinary kallikrein excretion may result from a direct effect of the mineralocorticoid (24), as a secondary response to sodium retention induced by the mineralocorticoid, as has been postulated by Adetuyibi and Mills (25), or indirectly from other mineralocorticoid effects. Since patients with LREH respond favorably to aminoglutethimide with a diuresis (26) while maintaining normokalemia chronically, some have postulated that the etiologic unknown mineralocorticoid induces sodium retention without increasing urinary potassium excretion. If urinary kallikrein increases secondary to 
sodium retention alone, then our data provide evidence against excess of this postulated different type of unknown sodium-retaining steroid in patients with LREH.

Our failure to find decreased urinary kallikrein excretion in either white or black patients with essential hypertension was unexpected. However, other investigators have subsequently failed to find a decrease in urinary kallikrein excretion in black hypertensive men (16) and in a small group of young white men with normal renin essential hypertension (27). We confirm the reported (16) decreased urinary kallikrein excretion in black vs. white men and extend these observations to women. It is notable that racial differences may have played a role in the earlier reports $(2,3)$ of decreased kallikrein excretion in hypertensive patients because this factor was not appreciated at the time. 8 of 11 of these hypertensive patients were reported to be black (3). The race of an additional 28 hypertensive patients in which urinary kallikrein excretion was measured was not specified. In contrast, 25 of 27 normal subjects were white (4) and the race was not specified in the remaining 30 normal subjects (3). A recent report (17) from this same group did not note decreased urinary kallikrein excretion in either hypertensive white or black patients, though the number of patients studied (four of each race) was too small for adequate evaluation. These data are contrasted to other reports from Italy $(19,28)$, Japan (18), and the United States $(16,20,29)$ in which decreased urinary kallikrein was noted in hypertensive patients. The factors which may have led to these conflicts include: $(a)$ racial differences, $(b)$ assay differences, $(c)$ comparison after stimulation with low sodium diet, and $(d)$ inclusion of patients with essential hypertension and slight renal insufficiency. On the basis of our data, we feel that this last factor may have been of particular importance. Mitas et al. (20) postulated that decreased kallikrein excretion in hypertensive patients with renal insufficiency may be a primary etiologic factor in the hypertension. However, urinary kallikrein was not determined by these investigators in patients with comparable renal insufficiency but normal blood pressure. Renal kallikrein appears to be localized in distal tubular cells (30). Urinary kallikrein excretion decreases acutely before the onset of proteinuria in immunologic and aminoglycoside-induced renal injury (31). In addition, urinary and kidney kallikrein decreases after renal blood flow is diminished by a unilateral renal artery clip. This decrease occurs whether or not hypertension ensues (32). Thus, both ischemia and decrease in renal tubular mass and possibly function can lead to a decrease in urinary kallikrein excretion. Hypertensive patients have long been noted to have subtle abnormalities in renal function early in the course of hypertension. The earliest abnormalities include a decrease in tubular function reflected by decreased tubular maximum for diodrast, which is com- monly accompanied by a decrease in renal blood flow and may precede a measurable decrease in glomerular filtration rate (33). These changes may also be expected to be accompanied by a decrease in urinary kallikrein excretion. Correlation of urinary kallikrein excretion with more sophisticated tests of renal tubular function would be helpful, though black hypertensive patients manifested an enhanced capacity for kallikrein stimulation as $\mathrm{C}_{\mathrm{cr}}$ improved (Fig. 7).

We have divided hypertensive patients into those with $\mathrm{C}_{\mathrm{cr}}$ above and below $80 \mathrm{ml} / \mathrm{min}$, as this appears to be the one best dividing line to identify those with decreased renal function when adult men and women up to age 70 are considered (34). Kallikrein excretion was decreased in both white and black hypertensive patients with $\mathrm{C}_{\mathrm{cr}}<80 \mathrm{ml} / \mathrm{min}$. When Florinef administration and low sodium diet were used to stimulate kallikrein excretion, the response of normal subjects vs. hypertensive patients with $\mathrm{C}_{\mathrm{cr}}>80 \mathrm{ml} / \mathrm{min}$ was similar except for the low renin hypertensives during low sodium diet. The lesser response in this patient subgroup is likely secondary to the lesser aldosterone stimulation achieved or to some other factor associated with their failure to achieve metabolic balance. The normal kallikrein response of black and white hypertensive patients with normal basal kallikrein excretion to potassium administration (17) also suggests that the renal kallikrein system is initially normal in essential hypertension. However, some investigators $(19,20)$ have noted decreased urinary kallikrein excretion in white hypertensive patients even when glomerular filtration rate was normal. Inexplicably, one of these groups noted no significant difference in urinary kallikrein excretion in white normals vs. hypertensives during low sodium diet in other studies (16). Urinary kallikrein excretion was significantly lower in black hypertensives (16) and normal renin hypertensives (29) during low sodium diet, but renal function and stimulation of urinary aldosterone excretion were not documented. Documentation of aldosterone stimulation is of particular interest because spironolactone administration returns urinary kallikrein excretion stimulated by low sodium diet to the base line (3). Thus, though certain discrepancies exist with respect to urinary kallikrein excretion in normals vs. hypertensives, our failure to confirm a decrease in urinary kallikrein excretion in patients with essential hypertension dampens enthusiasm somewhat for the postulate $(2,3)$ of a significant role of the renal kallikrein-kinin system in the initiation of essential hypertension. The possibility remains that it may influence the maintenance or acceleration of hypertension or that it may contribute to the initiation of hypertension in a small subgroup of patients. However, these conclusions are hampered by the realization that the validity of using urinary kallikrein excretion to assess renal kallikrein function 
remains unknown. In humans there is good correlation between urinary kallikrein, as determined by alkaline$\rho$-tosyl-L-arginine methyl ester esterase activity in our studies, and bioassayable kinin-generating activity (4, $16,36)$ under regular, low sodium, and high sodium dietary conditions (4). Nonetheless, human urine contains nonkallikrein esterases, kallikrein inhibitors, kininases, and inactive kallikrein or prokallikrein which may confound the use of urinary kallikrein determination by any method as an index of renal kallikrein function (37). Furthermore, kallikrein activity changes with prolonged (over 1-2 mo) storage of frozen or refrigerated urine. ${ }^{3}$ These methodological questions will remain for consideration for quite some time. The significance of increased kallikrein excretion in some cases of mineralocorticoid hypertension and the physiology of the kallikrein-kinin system in sodium metabolism remains unknown.

\section{ACKNOWLEDGMENTS}

We thank Toni Ziegler and Johanna Arnold for technical assistance, Carol Fairchild, LaVon Kuhnert, and Carol Poindexter for help with some of the patient studies, Ellen Rudisill for secretarial assistance, and Dr. Celso Gomez-Sanchez for helpful suggestions.

This work was supported by National Institutes of Health grants RO1-HL18730 and MOI-RR-00633 and grants-in-aid from the American Heart Association and its Texas Affiliate.

\section{REFERENCES}

1. Elliot, A. H., and F. R. Nuzum. 1934. Urinary excretion of a depressor substance (kallikrein of Frey and Kraut) in arterial hypertension. Endocrinology. 18: 462-474.

2. Margolius, H. S., J. J. Pisano, R. Geller, and A. Sjoedsma. 1971. Altered urinary kallikrein excretion in human hypertension. Lancet. II: 1063-1065.

3. Margolius, H. S., D. Horwitz, J. J. Pisano, and H. R. Keiser. 1974. Urinary kallikrein excretion in hypertensive man. Relationship to sodium intake and sodium-retaining steroids. Circ. Res. 35: 820-825.

4. Margolius, H. S., D. Horwitz, R. G. Geller, R. W. Alexander, J. R. Gill, Jr., J. J. Pisano, and H. R. Keiser. 1974. Urinary kallikrein excretion in normal man. Relationship to sodium intake and sodium-retaining steroids. Circ. Res. 35: 812-819.

5. Margolius, H. S., R. Geller, W. De Jong, J. J. Pisano, and A. Sjoerdsma. 1972. Altered urinary kallikrein excretion in rats with hypertension. Circ. Res. 30: 358-362.

6. Geller, R. G., H. S. Margolius, J. J. Pisano, and H. R. Keiser. 1972. Effects of mineralocorticoids, altered sodium intake, and adrenalectomy on urinary kallikrein in rats. Circ. Res. 31: 857-861.

7. Sennett, J. A., R. D. Brown, D. P. Island, L. R. Yarbo, J. T. Watson, P. E. Slaton, J. W. Hollifield, and G. W. Liddle. 1975. Evidence for a new mineralocorticoid in patients with low-renin essential hypertension. Circ. Res. 36(Suppl. 1): 2-9.

8. Kaplan, N. M., D. C. Kem, O. B. Holland, N. J. Kramer, J. R. Higgins, and C. E. Gomez-Sanchez. 1974. The intra-

${ }^{3}$ Unpublished observations. venous furosemide test: a simple way to evaluate renin responsiveness. Ann. Intern. Med. 133: 205-211.

9. Kem, D. C., M. H. Weinberger, D. M. Mayes, and C. A. Nugent. 1971. Saline suppression of plasma aldosterone in hypertension. Arch. Intern. Med. 128: 380-386.

10. Luft, F. C., C. E. Grimm, L. R. Willis, J. T. Higgins, Jr., and M. H. Weinberger. 1977. Natriuretic response to saline infusion in normotensive and hypertensive man. The role of renin suppression in exaggerated natriuresis. Circulation. 55: 779-784.

11. Biglieri, E. G., M. A. Herron, and N. Brust. 1966. 17hydroxylation deficiency in man. J. Clin. Invest. 45: 1946- 1954.

12. Haber, E., T. Koerner, L. B. Page, B. Kliman, and A. Purnode. 1969. Application of radioimmunoassay for angiotensin I to the physiologic measurements of plasma renin activity in normal human subjects. J. Clin. Endocrinol. Metab. 29: 1349-1355.

13. Gomez-Sanchez, C. E., D. C. Kem, and N. M. Kaplan. 1973. A radioimmunoassay for plasma aldosterone by immunologic purification. J. Clin. Endocrinol. Metab. 36: 795-798.

14. Langan, J., R. Jackson, E. V. Adlin, and B. J. Channick. 1974. A simple radioimmunoassay for urinary aldosterone. J. Clin. Endocrinol. Metab. 38: 189-193.

15. Goldstein, A. 1964. Biostatistics: An Introductory Text. Macmillan, Inc., New York.

16. Levy, S. B., J. J. Lilley, R. P. Frigon, and R. A. Stone. 1977. Urinary kallikrein and plasma renin activity as determinants of renal blood flow. The influence of race and dietary sodium intake. J. Clin. Invest. 60: 129-138.

17. Horwitz, D., H. S. Margolius, and H. R. Keiser. 1978. Effects of dietary potassium and race on urinary excretion of kallikrein and aldosterone in man. J. Clin. Endocrinol. Metab. 47: 296-299.

18. Seino, M., K. Abe, Y. Otsuka, T. Saito, N. Irokawa, M. Yasujima, S. Ciba, and K. Yoshinaga. 1975. Urinary kallikrein excretion and sodium metabolism in hypertensive patients. Tohoku J. Exp. Med. 116: 359-367.

19. Lechi, A., G. Covi, C. Lechi, A. Corquati, E. Arosio, M. Zatti, and L. A. Scuro. 1978. Urinary kallikrein excretion and plasma renin activity in patients with essential hypertension and primary aldosteronism. Clin. Sci. Mol. Med. 55: 51-55.

20. Mitas, J. A., II, S. B. Levy, R. Holle, R. P. Frigon, and R. A. Stone. 1978. Urinary kallikrein activity in the hypertension of renal parenchymal disease. N. Engl. J. Med. 299: 162- 165 .

21. Miller, J. H., and N. W. Shock. 1953. Age differences in renal tubular response to antidiuretic hormone. J. Gerontol. 8: 446-450.

22. Davies, D. F., and N. W. Shock. 1950. Age changes in glomerular filtration rate, effective renal plasma flow, and tubular excretory capacity in adult males. J. Clin. Invest. 29: 496-507.

23. Hunt, T. K., M. Schambelan, and E. G. Biglieri. 1975. Selection of patients and operative approach in primary aldosteronism. Ann. Surg. 182: 353-361.

24. Margolius, H. S., J. Chao, and T. Kaizu. 1976. The effects of aldosterone and spironolactone on renal kallikrein in the rat. Clin. Sci. Mol. Med. 51(Suppl. 3): 279S-282S.

25. Adetuyibi, A., and I. M. Mills. 1972. Relation between urinary kallikrein and renal function, hypertension, and excretion of sodium and water in man. Lancet. II: 203207.

26. Liddle, G. W., J. W. Hollifield, P. E. Slaton, and H. M. Wilson. 1976. Effects of various adrenal inhibitors in low- 
renin essential hypertension. J. Steroid Biochem. 7: 937-940.

27. Lawton, W. J., and A. E. Fitz. 1977. Urinary kallikrein in normal renin essential hypertension. Circulation. 56: 856-859.

28. Greco, A. V., G. Porcelli, H. R. Croxatto, G. Fedeli, and G. Ghirlanda. 1974. Apertensione arteriosa e callicreina urinaria. Minerva Med. 65: 3058-3062.

29. Mersey, J. H., G. H. Williams, R. Emanuel, R. G., Dluhy, P. Y. Wong, and T. J. Moore. 1979. Plasma bradykinin levels and urinary kallikrein excretion in normal renin essential hypertension. J. Clin. Endocrinol. Metab. 48: 642-647.

30. Ward, P. E., C. D. Gedney, R. M. Dowben, and E. G. Erdos. 1975. Isolation of membrane-bound renal kallikrein and kininase. Biochem. J. 151: 755-758.

31. Glasser, R. J., and A. F. Michael. 1976. Urinary kallikrein in experimental renal disease. Lab. Invest. 34: 616-622.
32. Lechi, C., G. P. Rasi, G. Lovi, E. Arosio, G. Zannini, and A. Lechi. 1976. Urinary and kidney kallikrein in hypertensive rats. Biomedicine (Paris). 25: 236-238.

33. Goldring, W., H. Chasis, H. A. Ranges, and H. W. Smith. 1941. Effective renal blood flow in subjects with essential hypertension. J. Clin. Invest. 20: 637-653.

34. Brod, J. 1973. The Kidney. Butterworth \& Co., Ltd., London. 88.

35. Levy, S. B., R. P. Frigon, and R. A. Stone. 1978. The relationship of urinary kallikrein activity to renal salt and water excretion. Clin. Sci. Mol. Med. 54: 39-45.

36. Seino, M., K. Abe, Y. Kakurai, N. Irokawa, M. Yasujima, S. Chiba, Y. Otsuka, and K. Yoshinaga. 1977. Effect of spironolactone on urinary kallikrein excretion in patients with essential hypertension and in primary aldosteronism. Tohoku J. Exp. Med. 121: 111-119.

37. Levinsky, N. G. 1979. The renal kallikrein-kinin system. Circ. Res. 44: 441-451. 